\title{
DAMPAK INFRASTRUKTUR TRANSPORTASI TERHADAP PERTUMBUHAN EKONOMI DI INDONESIA MENGGUNAKAN REGRESI DATA PANEL
}

\author{
Fitri Kartiasih \\ Politeknik Statistika STIS \\ Jln. Otto Iskandardinata Jakarta \\ E-mail : fkartiasih@stis.ac.id \\ diterima: 22/2/2019; direvisi: 22/3/2019; diterbitkan: 31/3/2019
}

\begin{abstract}
Infrastructure plays an important role in increasing economic growth. One of them is infrastructure in the transportation sector. The better a transportation network, the better the accessibility so that economic activities between regions are also growing. The problem discussed in this study is the influence of transportation infrastructure on Indonesia's economic growth. The transportation infrastructure used is the length of the road in good and medium conditions, the number of goods cars, the number of passenger cars, the number of buses, the number of motorbikes, the number of terminals, the arrival flow of aircraft, and the flow of loading and unloading of goods at the port. The data used is panel data with a period of 2010-2014 for 30 provinces in Indonesia. To choose the best model, test for panels such as Chow Test and Hausman Test is done so that the fixed effect model is obtained as the best model. Then the classical assumptions were tested such as normality, multicollinearity, heteroscedasticity, and autocorrelation. The results showed that goods cars, passenger cars, motorbikes, loading and unloading goods, aircraft currents, and the number of terminals had a significant effect on economic growth while the length of the road and the number of buses did not significantly affect economic growth.
\end{abstract}

Keywords: transportation, panel data, economic growth, fixed effect model

\section{PENDAHULUAN}

Pembangunan nasional suatu negara pada dasarnya bertujuan untuk menciptakan kesejahteraan masyarakatnya. Untuk mewujudkan tujuan nasional tersebut diperlukan berbagai kegiatan yang mendukung perkembangan di segala aspek termasuk salah satunya pada aspek perekonomian. Perkembangan perekonomian suatu negara dapat terlihat dari angka pertumbuhan ekonomi yang juga merupakan salah satu indikator pembangunan untuk mengevaluasi hasil dari program-program yang telah dilaksanakan maupun sebagai acuan pembangunan yang akan datang.

Pertumbuhan ekonomi dapat dipengaruhi oleh banyak hal salah satunya adalah infrastruktur. Adanya infrastruktur ini terkait erat dengan kelancaran mobilisasi dan distribusi barang dan jasa yang secara tidak langsung menentukan pertumbuhan ekonomi melalui kelancaran kegiatan ekonomi masyarakat. Merujuk pada publikasi World Bank yang dikutip oleh Maryaningsih dkk (2014) dinyatakan bahwa infrastruktur berperan penting dalam meningkatkan pertumbuhan ekonomi dimana pertumbuhan ekonomi yang lebih tinggi dijumpai pada wilayah dengan tingkat ketersediaan infrastruktur yang mencukupi. Seperti yang telah disebutkan sebelumnya, infrastruktur yang cukup vital berkaitan dengan pertumbuhan ekonomi adalah infrastruktur transportasi. Dengan adanya infrastruktur transportasi yang memadai, selain untuk kelancaran mobilitas dan distribusi juga sebagai stimulus para investor untuk menanam modal karena mereka akan lebih tertarik pada wilayah yang aksesibilitasnya baik sehingga 


\section{Jurnal Ilmiah Ekonomi dan Bisnis}

Vol. 16. No.1, Maret 2019: 67-77

EISSN : $2442-9813$

ISSN : $1829-9822$

kegiatan perekonomian menjadi lancar. Semakin baik suatu jaringan transportasi maka aksesibilitasnya juga semakin baik sehingga kegiatan ekonomi antar wilayah juga semakin berkembang (Hurst, 1974).

Menurut laporan World

Economic Forum dapat diketahui bahwa tingkat daya saing Indonesia masih tertinggal terutama pada pilar infrastruktur, pilar kesiapan teknologi dan pilar inovasi. Secara lebih spesifik, kendala pilar infrastruktur antara lain bersumber dari masih rendahnya kualitas jalan, pelabuhan, bandara, kereta hingga kualitas pasokan listrik. Sedangkan angka pertumbuhan ekonomi dari tahun ke tahun cukup fluktuatif namun beberapa tahun terakhir melambat yaitu tahun 2011 sampai dengan tahun 2015 kemudian mulai merangkak lagi di tahun 2016 (dapat dilihat pada Gambar 1).

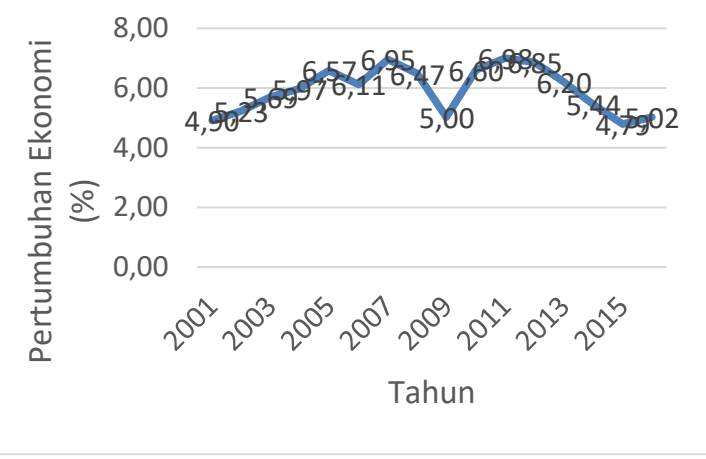

Sumber : Badan Pusat Statistik

Gambar 1.

Pertumbuhan Ekonomi di Indonesia

Tahun 2001 - 2016

Dalam dua tahun terakhir ini terjadi perubahan target pertumbuhan ekonomi dalam Anggaran Pendapatan dan Belanja Negara (APBN) dari 5,2\% menjadi 5,1\% sedangkan tahun 2017 direvisi dari 5,3\% menjadi 5,2\% karena ada pemangkasan anggaran (Sugianto,2016). Pemangkasan anggaran ini diharapkan dapat tertolong dengan adanya kenaikan investasi yang bermuara pada pertumbuhan ekonomi.
Untuk itu diperlukan berbagai upaya untuk menarik para investor salah satunya adalah dengan pembangunan infrastruktur di daerah-daerah yang masih belum memadai.

Berkaitan dengan hal itu, sebagaimana dengan program pemerintah dalam 5 tahun terakhir ini tengah memfokuskan pada pembangunan infrastruktur. Program pembangunan infrastruktur sarana transportasi tersebut tak lain dimaksudkan untuk menarik minat para investor.

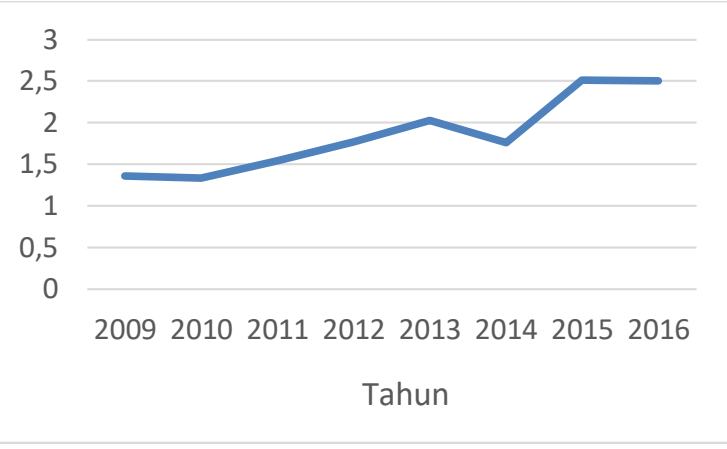

Sumber : Kementrian Keuangan (diolah) Gambar 2

Rasio Anggaran Infrastruktur terhadap Produk Domestik Bruto Tahun 20092016

Berdasarkan pemaparan di atas, memunculkan sebuah dugaan bahwa kurang memadainya infrastruktur transportasi menjadi salah satu penyebab melambatnya pertumbuhan ekonomi di Indonesia beberapa tahun terakhir. Dengan demikian, diperlukan kajian empiris mengenai Pengaruh Infrastruktur Transportasi terhadap Pertumbuhan Ekonomi di Indonesia agar kebijakan berinvestasi dalam sektor transportasi tepat sasaran sehingga target pertumbuhan ekonomi yang tinggi dapat tercapai. Hal itulah yang melatarbelakangi penelitian ini yang akan menganalisis kaitan antara pembangunan infrastruktur sarana transportasi dan pertumbuhan ekonomi. Jadi tujuan dalam penelitian ini adalah untuk mengetahui gambaran umum 
perkembangan infrastruktur transportasi darat, laut dan udara di Indonesia serta untuk menganalisis pengaruh infrastruktur transportasi terhadap pertumbuhan ekonomi di Indonesia.

\section{TINJAUAN PUSTAKA}

Mankiw (2003) menyatakan bahwa pertumbuhan ekonomi menunjukkan sejauh mana aktivitas perekonomian akan menghasilkan tambahan pendapatan masyarakat pada suatu periode tertentu. Karena pada dasarnya aktivitas perekonomian adalah suatu proses penggunaan faktor-faktor produksi untuk menghasilkan output, maka proses ini pada gilirannya akan menghasilkan suatu aliran balas jasa terhadap faktor produksi yang dimiliki masyarakat. Todaro (2003) mengatakan ada tiga faktor atau komponen utama dalam pertumbuhan ekonomi. Pertama, akumulasi modal yang meliputi semua bentuk dan jenis investasi baru yang ditanamkan pada tanah, peralatan fisik dan sumber daya manusia. Kedua, pertumbuhan penduduk yang beberapa tahun selanjutnya dengan sendirinya membawa pertumbuhan angkatan kerja. Ketiga, kemajuan teknologi Selanjutnya ditambahkan oleh Mankiw (2003) indikator yang digunakan untuk mengukur pertumbuhan ekonomi adalah tingkat pertumbuhan Produk Domestik Bruto (PDB). Ada beberapa alasan yang mendasari pemilihan pertumbuhan ekonomi menggunakan Produk Domestik Bruto (PDB) bukan indikator lainnya di antaranya adalah bahwa PDB merupakan jumlah nilai tambah yang dihasilkan oleh seluruh aktivitas produksi di dalam perekonomian, hal ini berarti peningkatan PDB juga mencerminkan peningkatan balas jasa kepada faktor-faktor produksi yang digunakan dalam aktivitas produksi tersebut.

Romer dalam Capello (2009) menyatakan bahwa selain kemajuan teknologi, salah satu sumber pertumbuhan adalah berasal dari eksternalitas yang terjadi akibat adanya akumulasi stok pengetahuan teknis yang kemudian berkolaborasi dengan modal tetap pada suatu waktu tertentu dalam mencapai tingkat output tertentu. Lucas dalam Capello (2009) menyatakan hal yang sama dengan apa yang dikemukakan Romer, bahwa modal yang menentukan tingkat output yang dicapai dapat diklasifikasikan menjadi dua bagian yaitu modal fisik dan modal manusia. Kombinasi keduanya dalam fungsi produksi dapat meningkatkan tingkat output tertentu.

Teori pertumbuhan endogen menyatakan bahwa perbaikan dan kemajuan teknologi dihasilkan dari investasi yang secara langsung menyebabkan pertumbuhan, sehingga investasi dapat berkontribusi pada pertumbuhan ekonomi jangka panjang (Economic Planning Advisory Commission, 1995). Reungsri (2010) juga menyatakan bahwa investasi merupakan salah satu faktor penting pada model pertumbuhan endogen, investasi dapat menyebabkan perbaikan pada kapasitas produksi dan kenaikan laba yang berimplikasi pada adanya pertumbuhan ekonomi. Pada teori pertumbuhan neoklasik, adanya asumsi "law of diminishing return" membawa pada argumentasi bahwa investasi tidak mampu memengaruhi pertumbuhan. Namun pada teori pertumbuhan endogen, meskipun dibawah asumsi "law of diminishing return" investasi tetap mampu meningkatkan pertumbuhan. Sebagai contoh, adanya kemajuan teknologi yang didanai dari investasi akan mampu meningkatkan pertumbuhan ekonomi, selain itu, tenaga kerja ahli yang didapat dari hasil pendidikan maupun pelatihan juga dapat meningkatkan pertumbuhan ekonomi. Berdasarkan pemikiran tersebut, dalam penelitian ini peranan investasi terutama investasi infrastruktur terhadap 
Jurnal Ilmiah Ekonomi dan Bísnís

Vol. 16. No.1, Maret 2019: 67-77

EISSN : $2442-9813$

ISSN : $1829-9822$

pertumbuhan ekonomi didekati dengan menggunakan model pertumbuhan endogen.

\section{METODE PENELITIAN}

Data-data yang digunakan dalam penelitian ini merupakan data sekunder yang bersumber dari publikasi Badan Pusat Statistik dan Departemen Perhubungan untuk 30 Provinsi di Indonesia tahun 2010 hingga 2014, yaitu terdiri dari data Produk Domestik Regional Bruto (PDRB), panjang jalan baik dan sedang, jumlah mobil barang, jumlah mobil penumpang, jumlah bus, jumlah sepeda motor, jumlah terminal, jumlah arus pesawat (kedatangan dan keberangkan), jumlah arus barang (bongkar \& muat) dan jumlah penduduk. Provinsi yang tidak dicakup adalah DI Yogyakarta, Kalimantan Utara, Papua Barat dan Sulawesi Barat dikarenakan beberapa data yang diperlukan tidak tersedia untuk empat provinsi tersebut.

Analisis yang digunakan dalam penelitian ini adalah analisis regresi data panel, dimana model penelitian ini dapat dituliskan sebagai berikut: $\ln P D R B_{i t}=\beta_{0}+\beta_{1} \ln J A L A N_{i t}+$

$$
\begin{aligned}
& \beta_{2} \ln \mathrm{MOBA}_{i t}+ \\
& \beta_{3} \ln \mathrm{MOPEN}_{i t}+\beta_{4} \ln B \\
& \beta_{5} \ln \mathrm{MOTOR}_{i t}+ \\
& \beta_{6} \ln \mathrm{TERMINAL_{it }}+ \\
& \beta_{7} \ln \mathrm{PESAWAT} \mathrm{T}_{i t}+ \\
& \beta_{8} \ln \mathrm{LABUH}_{i t}+e_{i t}
\end{aligned}
$$$$
\beta_{3} \ln M O P E N_{i t}+\beta_{4} \ln B U S_{i t}+
$$

Keterangan :

$$
\begin{array}{cc}
\text { PDRB } & =\text { PDRB per jumlah penduduk } \\
& \text { provinsi ke } i \text { tahun } t \text { (miliar } \\
& / 1000 \text { jiwa) } \\
J A L A N_{i t} & =\text { Panjang Jalan Baik dan } \\
& \text { Sedang per jumlah penduduk } \\
& \text { Provinsi ke } i \text { tahun } t \\
& \text { (km } / 1000 \text { jiwa) } \\
\text { MOBA } A_{i t} & \text { Jumlah Mobil Barang } \\
& \text { per jumlah penduduk } \\
& \text { Provinsi ke } i \text { tahun } t \\
& \text { (unit/1000 jiwa) }
\end{array}
$$

MOPEN $_{i t} \quad=$ Jumlah Mobil Penumpang per jumlah Penduduk Provinsi ke $i$ tahun $t$ (unit/1000 jiwa)

$B U S_{i t} \quad=$ Jumlah Bus per Jumlah Penduduk Provinsi ke $i$ tahun $t$ (unit/1000 jiwa)

MOTOR $_{i t}=$ Jumlah sepeda motor per jumlah penduduk provinsi ke $i$ tahun $t$

$$
\text { (unit/1000 jiwa) }
$$

TERMINAL $L_{i t}=$ Jumlah Terminal per jumlah penduduk provinsi ke $i$ tahun $t$ (unit/1000

$$
\text { jiwa) }
$$

PESAWAT $_{i t}=$ Jumlah Arus Pesawat (kedatangan dan keberangkan) per jumlah penduduk provinsi ke $i$ tahun $t$ (kali/1000 jiwa)

${ }^{L A B U H} H_{i t} \quad=$ Jumlah Arus Barang (bongkar \& Muat) di Pelabuhan per jumlah penduduk (ton/1000 jiwa)

$e_{i t} \quad=$ residual

$\beta_{0} \quad=$ intersep

$\beta_{1}, \beta_{2}, \ldots, \beta_{8}=$ koefisien regresi

ln $\quad=$ logaritma natural

b. Teknik Pengujian

Dalam membangun model data panel, terdapat tiga model yang dijadikan acuan, yaitu common effect model, fixed effect model dan random effect model. Untuk mengetahui model terbaik, penulis menggunakan dua uji, yaitu uji:

- Chow Test

$H_{0}: \mu_{i}$

$=0($ common effect model $)$

$H_{1}: \mu_{i} \neq 0$ (fixed effect model)

Statistik uji :

$F_{o b s}=\frac{(R R S S-U R S S) /(N-1)}{U R S S /(N T-N-K)} \sim F_{(\alpha ;(N-1) ;(N T-N-K))}$

Keterangan :

$\mathrm{N} \quad$ : jumlah individu

$\mathrm{T}$ : jumlah periode observasi

K : Jumlah variabel independen 
RRSS : Sum Square Error Common Effect Model

URSS : Sum Square Error Fixed Effect Model

Apabila nilai $F_{o b s}$ lebih besar dari nilai $F_{\text {tabel }}$ atau $p$-value lebih kecil dari alpha, maka hasilnya akan menolak $H_{0}$. Sehingga dapat diambil kesimpulan fixed effect model lebih baik daripada common effect model.

- Hausman Test

$H_{0}:\left(\mu_{i} \mid x_{i t}\right)$

$=0$ (random effect model $)$

$H_{1}:\left(\mu_{i} \mid x_{i t}\right)$

$\neq 0$ (fixed effect model)

a. Uji Asumsi

- Uji Lagrange Multiplier (LM test): Heterogenitas

$H_{0}: \sigma_{1}^{2}=\sigma^{2}$ (homoskedastis)

$H_{1}: \sigma_{1}^{2} \neq \sigma^{2}$ (heteroskedastis)

$L M=\frac{T}{2} \sum_{i=1}^{N}\left[\frac{\widehat{\sigma}_{i}^{2}}{\hat{\sigma}^{2}}-1\right]^{2} \sim X_{(N-1)}^{2}$

- Normalitas

Untuk menguji normalitas menggunakan histogram normality test.

$H_{0}$ : Residual Berdistribusi Normal

$H_{1}$ : Residual Tidak Berdistribusi Norr

Jika $p$-value > tingkat signifikansi maka data berdistribusi normal

- Multikolineritas

Untuk menguji ada tidaknya gejala multikolinearitas dalam model maka dilakukan pengujian korelasi antar variabel bebasnya.

- Autokorelasi

Untuk menguji Serial Correlation (autokorelasi) menggunakan uji Durbin Watson

$H_{0}: \rho=0$ (non-autokorelasi)

$H_{1}: \rho>0$ (autokorelasi)

Jika $p$-value $>$ tingkat signifikansi maka tidak terjadi autokorelasi

\section{HASIL DAN PEMBAHASAN}

Sejak tahun 2000 - 2001, jumlah kendaraan bermotor di Indonesia selalu mengalami peningkatan yang terlihat pada Gambar 3 di bawah ini.

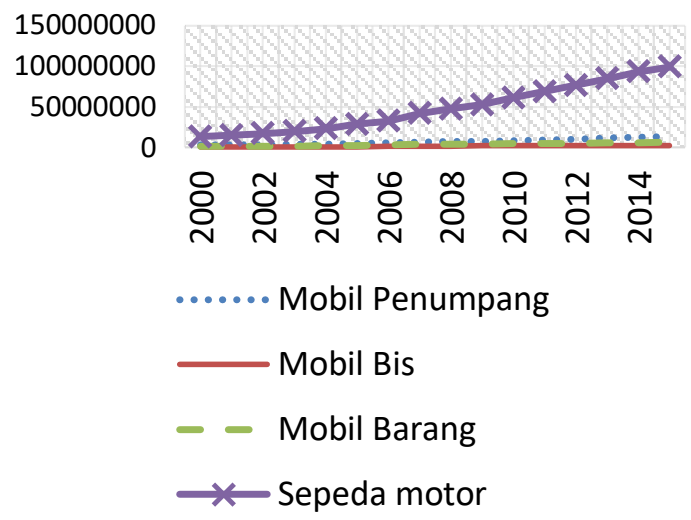

Gambar 3. Perkembangan Jumlah

Kendaraan Bermotor di

Indonesia Menurut Jenis Tahun 2000 - 2015 (unit)

Selain pesatnya pertumbuhan jumlah kendaraan bermotor, jumlah kendaraan bermotor juga tidak tersebar merata pada wilayah di Indonesia seperti yang nampak pada gambar di bawah ini.

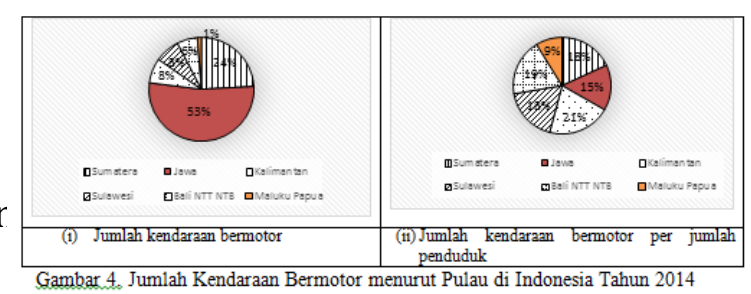

Dari Gambar 4 terlihat bahwa lebih dari setengah jumlah kendaraan bermotor di Indonesia berada di Pulau Jawa yaitu sebesar 53\%. Peringkat kedua terbesar selanjutnya adalah berada di Pulau Sumatera sebesar 24\%. Peringkat ketiga berada di Pulau Kalimantan dan Sulawesi sebesar 8\%, keempat di Pulau Bali, NTB, dan NTT sebesar 6\%, dan peringkat terakhir berada di Pulau Papua yaitu hanya sebear $1 \%$ dari jumlah seluruh kendaraan bermotor di Indonesia. Banyaknya jumlah kendaraan bermotor merupakan salah satu gambaran besarnya kegiatan perekonomian di wilayah tertentu. Tidak meratanya infrastruktur tersebut menandakan bahwa selama ini perekonomian cenderung berfokus pada di Pulau Jawa. 


\section{Jurnal Ilmiah Ekonomi dan Bisnis}

Vol. 16. No.1, Maret 2019: 67-77

EISSN : $2442-9813$

ISSN : $1829-9822$

Berdasarkan Gambar 4 (ii) terlihat bahwa jumlah kendaraan per jumlah penduduk di setiap wilayah kelompok pulau di Indonesia cenderung sama. Meskipun jumlah kendaraan bermotor paling banyak berada di Pulau Jawa, namun rasio jumlah kendaraan bermotor dengan jumlah penduduk yang paling besar justru berada di Pulau Kalimantan. Hal ini mungkin disebabkan wilayah Pulau Kalimantan yang luas sehingga memerlukan infrastruktur transportasi yang lebih banyak agar mobilitas antar wilayah dan aktivitas di pulau tersebut mudah atau lancar.

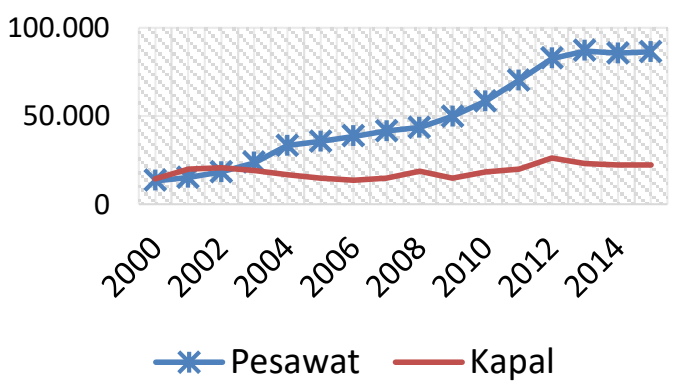

Gambar 5. Perkembangan Jumlah Keberangkatan Penumpang Pesawat dan Kapal di Indonesia Tahun 2000 - 2014 (Ribuan)

Jumlah penumpang pesawat jauh lebih pesat pertumbuhannya daripada penumpang kapal laut. Pada awalnya terlihat penumpang pesawat dan kapal laut cenderung sama. Namun, terlihat penumpang kapal laut cenderung tidak mengalami perkembangan dan hampir sama setiap tahunnya berbeda dengan penumpang pesawat yang semakin banyak. Hingga tahun 2015 jumlah penumpang pesawat mencapai 86 ribu jiwa. Hal ini mencerminkan bahwa orangorang cenderung lebih suka berpergian dengan menggunakan pesawat dibandingkan dengan kapal laut. Selain lebih cepat dan efisien, harga tiket yang semakin bersaing juga mungkin menjadi faktor pesawat semakin disukai penumpang untuk pergi kesuatu tempat.

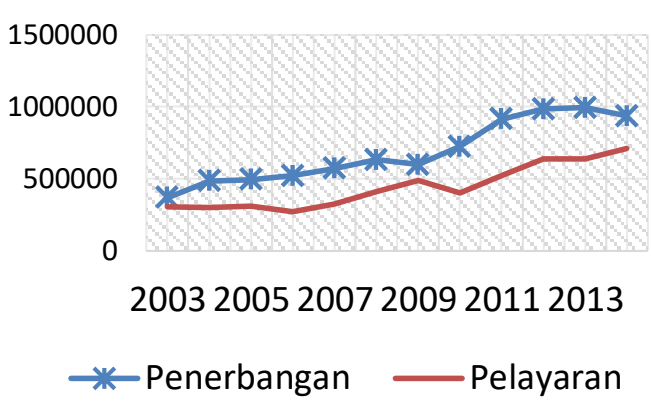

Gambar 6. Perkembangan Volume Bongkar Muat Barang Dalam Negeri Tahun 2003 - 2014 (ton)

Perkembangan volume bongkar muat dalam negeri di Indonesia antara penerbangan dengan pelayaran sama-sama meningkat. Artinya, untuk mengirim atau memindahkan barang-barangnya, orangorang cenderung sama untuk memilih angkutan antara pelayaran atau penerbangan. Dengan demikian, baik udara maupun laut sama-sama memiliki kontribusi yang cukup penting dalam mobilitas barang-barang dan pendistribusian barang yang akan memicu dan memeratakan pertumbuhan ekonomi di wilayah-wilayah di indonesia.

Untuk mengetahui pengaruh antara infrastruktur transportasi terhadap pertumbuhan ekonomi di Indonesia, digunakan analisis regresi data panel terhadap 30 Provinsi di Indonesia tahun 2010 - 2014. Berikut adalah hasil dari model regresi data panel dari variabelvariabel infrastruktur terhadap PDRB dengan tiga pendekatan model.

Tabel 1. Hasil running 3 model data panel

\begin{tabular}{|c|c|c|c|}
\hline \multicolumn{4}{|c|}{ Variabel dependen $=\ln ($ PDRB $)$} \\
\hline $\begin{array}{l}\text { Variabel } \\
\text { independen }\end{array}$ & $\begin{array}{l}\text { Common } \\
\text { Effect }\end{array}$ & Fixed Effect & $\begin{array}{l}\text { Random } \\
\text { Effect }\end{array}$ \\
\hline Konstanta & $0.842698 * * *$ & $2.383806^{* * *}$ & $2.339287 * * *$ \\
\hline $\ln (\mathrm{JALAN})$ & $-0.328507 * * *$ & -0.022668 & $-0.123894 *$ \\
\hline $\ln (\mathrm{MOBA})$ & 0.039239 & $0.081642 * * *$ & $0.093075^{* * *}$ \\
\hline $\ln (\mathrm{MOPEN})$ & $0.266629 * * *$ & $0.084415^{* * * *}$ & 0.097958 *** \\
\hline $\ln$ (BUS) & -0.023789 & -0.004824 & -0.004621 \\
\hline $\ln (\mathrm{MOTOR})$ & -0.001882 & $0.008353^{* *}$ & $0.008577 * *$ \\
\hline $\ln$ (TERMINAL) & 0.077121 & $0.020302 *$ & $0.017427 *$ \\
\hline $\ln ($ PESAWAT) & 0.028704 & $0.143577^{* * *}$ & $0.130404 * * *$ \\
\hline $\ln (\mathrm{LABUH})$ & $0.262502 * * *$ & $0.030376^{* * *}$ & $0.033633^{* * *}$ \\
\hline $\begin{array}{l}\text { Prob. } \\
\text { Statistics) }\end{array}$ & 0.00000 & 0.00000 & 0.00000 \\
\hline R-Square & 0.651301 & 0.996270 & 0.633100 \\
\hline R-Square Adjstd & 0.631516 & 0.995038 & 0.612283 \\
\hline
\end{tabular}


Dari Tabel 1 dapat dilihat bahwa ketiga model memiliki nilai Prob. $(F-$ Statistics) yang lebih kecil dari nilai $\alpha=$ $10 \%$, artinya, pada ketiga model tersebut, semua variabel bebasnya secara bersamasama berpengaruh terhadap pertumbuhan ekonomi. Terlihat pula bahwa model dengan Fixed Effect mempunyai $R$ squared yang lebih besar. Dengan menggunakan $\alpha=10 \%$, maka variabel bebas yang sama sekali tidak berpengaruh terhadap pertumbuhan ekonomi adalah BUS (jumlah bis). Untuk mengetahui model yang terbaik maka dilakukan beberapa pengujian.

1. Uji Chow untuk menentukan model common effect atau fixed effect

$H_{0}: \mu_{1}=\mu_{2}=\cdots=\mu_{i}$

$=0$ (tidak ada perbedaan individual efek)

$H_{1}: \mu_{i} \neq 0$; minimal satu buah i

$\alpha=10 \%$

Tabel 2. Hasil Pengolahan Eviews:

Chow-Test

Redundant Fixed Effects Tests

Equation: Untitled

Test cross-section fixed effects

\begin{tabular}{lrr}
\hline \hline Effects Test & Statistic & \multicolumn{1}{c}{ d.f. } \\
\hline \hline Cross-section F & 357.231198 & $(29,112)$ \\
Cross-section Chi-square & 680.689986 & 29 \\
\hline \hline
\end{tabular}

Keputusan : karena nilai

Prob.(Cross-section F) lebih kecil daripada alpha $(0,10)$ maka tolak $H_{0}$. Jadi dapat disimpulkan bahwa dengan tingkat signifikansi $10 \%$, terdapat perbedaan individual efek. Artinya, model yang terpilih adalah model fixed effect.

Tabel 3. Hasil Pengolahan Eviews: Hausman-Test
Correlated Random Effects - Hausman Test

Equation: Unitited

Test cross-section random effects

\begin{tabular}{lccc}
\hline \hline Test Summary & Chi-Sq. Statistic & Chi-Sq. df. & Prob. \\
\hline \hline Cross-section random & 27.348761 & 8 & 0.0006 \\
\hline \hline
\end{tabular}

Uji Hausman untuk menentukan model fixed effect atau random effect.

$H_{0}: E\left(u_{i t} \mid X_{i t}\right)$

$=0$ (tidak ada korelasi antar variabel

bebas dengan individu efek)

$H_{1}: E\left(u_{i t} \mid X_{i t}\right)$

$\neq 0$ (ada korelasi antar variabel bebas dengan individu efek)

$\alpha=10 \%$

Keputusan : karena nilai Prob.(Cross-section random) lebih kecil daripada alpha $(0,10)$ maka tolak $H_{0}$. Jadi dapat disimpulkan bahwa dengan tingkat signfikansi $10 \%$, terdapat korelasi antar variabel bebas dengan individual efek. Artinya model yang terpilih adalah model fixed effect.

Dari dua uji hasil di atas, maka model regresi data panel yang terbaik adalah model fixed effect. Selanjutnya dilakukan uji asumsi untuk mengetahui apakah model yang terpilih yaitu fixed effect serta estimasi yang digunakan sudah memenuhi asumsi.

1. Uji Lagrange Multiplier untuk menguji heteroskedastistas matriks kovarian

$H_{0}: \sigma_{i}^{2}$

$=\sigma$ (Struktur Matriks Varians

- Kovarians Homokedastis)

$H_{1}: \sigma_{i}^{2}$

$\neq \sigma$ (Struktur Matriks Varians

- Kovarians Heteroskedastis)

$\alpha=10 \%$

$L M=\frac{T}{2} \sum_{i=1}^{N}\left[\frac{\sigma_{1}^{2}}{\sigma^{2}}-1\right]^{2}=28.2351$

(7)

$\chi_{0,1 ; 29}^{2}=39.08747$ 
Jurnal Ilmiah Ekonomi dan Bísnis

Vol. 16. No.1, Maret 2019: 67-77

EISSN : $2442-9813$

ISSN : $1829-9822$

Keputusan : karena nilai LM lebih kecil daripada nilai $\chi_{0,1 ; 29}^{2}$ maka gagal tolak $H_{0}$

Kesimpulan : Dengan tingkat signifikansi $10 \%$, struktur matriks Varians $\quad-\quad$ Kovarians Homokedastis.

Karena Struktur Matriks varianskovariansnya sudah homokedastis, maka tidak perlu dilakukan uji cross-sectional correlation dan metode estimasi yang digunakan adalah LSDV (Least-Square Dummy Variable) sehingga metode estimasi yang digunakan sebelumnya pada fixed effect tidak berubah.

2. Uji Durbin untuk menguji serial correlation (autokorelasi)

$H_{0}: \rho=0$

$H_{1}: \rho>0$

$\alpha=10 \%$

Tabel 4. Hasil Pengolahan Eviews:

Durbin-Test

$\begin{array}{lrlll}\text { ihood } & 291.9479 & \text { Hannan-Ouinn critor } & 2076111 \\ \text { ic } & 808.6148 & \text { Durbin-Watson stat } & 2.074970 \\ \text { itatistic) } & 0.000000 & & \\ \text { Titik } & \text { kritis: } & \text { dL }=1.862 & \text { dan } & \text { 4- } \\ \text { dL=2.138 } & \end{array}$

Keputusan : karena nilai DurbinWatson stat berada diantara batas bawah (dL) dan 4-dL maka hasilnya gagal tolak $H_{0}$

Kesimpulan : Dengan tingkat signifikansi $10 \%$, maka tidak terjadi autokorelasi. Dengan demikian, asumsi tidak terjadi autokorelasi terpenuhi.

3. Uji Normalitas

$H_{0}$ : Residual Berdistribusi Normal

$H_{1}$ : Residual Tidak Berdistribusi Normal $\alpha=10 \%$

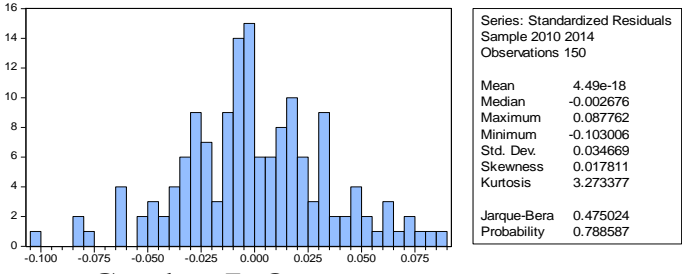

Gambar 7. Output Histogram

Probability Normal

Keputusan : Karena nilai Probability lebih besar dari alpha $(0,10)$ maka hasilnya gagal tolak $H_{0}$ Kesimpulan : Dengan tingkat signifikansi $10 \%$, residual berdistribusi normal. Dengan demikian, asumsi residual berdistribusi normal terpenuhi

4. Uji Multikolinearitas

$H_{0}$ : Tidak Terjadi Multikolinearitas $H_{1}$ : Terjadi Multikolinearitas

Keputusan : karena nilai korelasi antar variabel bebasnya tidak ada yang melebihi 0,8 maka gagal tolak $\mathrm{H}_{0}$

Kesimpulan : Tidak terjadi multikolinearitas

Dari serangkaian pengujian di atas, dapat disimpulkan bahwa model terbaik adalah fixed effect dengan metode estimasi LSDV (Least Square Dummy Variable) dimana model tersebut sudah memenuhi semua asumsi. Persamaaan regresi data panel yang terbentuk adalah

$$
\begin{aligned}
\widehat{\ln } \widehat{P R B}_{i t}= & \left(2,383806+\beta_{i} Q_{i t}\right)- \\
& 0,022668 \ln J A L A N_{i t}^{\prime}+ \\
& 0,081642 \ln M O B A_{i t}+ \\
& 0,084415 \ln M O P E N_{i t}- \\
& 0,004824 \ln B U S_{i t}^{\prime}+ \\
& 0.008353 \ln M O T O R_{i t}+ \\
& 0.020302 \ln T E R M I N A L_{i t}+ \\
& 0,143577 \ln P E S A W A T_{i t}+ \\
& 0,030376 \ln L A B U H_{i t}
\end{aligned}
$$


Keterangan : tanda (') tidak signifikan (alpha 10\%)

Dimana nilai $\beta_{i} Q_{i t}$ adalah efek individu

Tabel 5. Efek individu tiap provinsi provinsi dengan nilai sebagai berikut:

memiliki pengaruh positif dan signifikan terhadap pertumbuhan ekonomi sementara jumlah bis tidak berpengaruh signifikan terhadap pertumbuhan ekonomi. Berpengaruhnya mobil barang, mobil penumpang dan sepeda motor terhadap

\begin{tabular}{|r|l|r|c|l|r|r|l|r|}
\hline i & CROSSID & Effect & i & CROSSID & Effect & i & CROSSID & Effect \\
\hline 1 & Aceh & $-0,012$ & 11 & Jakarta & 1,318 & 21 & Kalsel & $-0,315$ \\
\hline 2 & Sumut & 0,062 & 12 & Jabar & 0,384 & 22 & Kaltim & 1,028 \\
\hline 3 & Sumbar & $-0,050$ & 13 & Jateng & $-0,015$ & 23 & Sulut & $-0,136$ \\
\hline 4 & Riau & 0,898 & 14 & Jatim & 0,210 & 24 & Sulteng & $-0,254$ \\
\hline 5 & Jambi & 0,154 & 15 & Banten & $-0,027$ & 25 & Sulsel & $-0,218$ \\
\hline 6 & Sumsel & 0,135 & 16 & Bali & $-0,377$ & 26 & Sultra & 0,007 \\
\hline 7 & Bengkulu & $-0,315$ & 17 & NTB & $-0,550$ & 27 & Gorontalo & $-0,366$ \\
\hline 8 & Lampung & 0,101 & 18 & NTT & $-0,941$ & 28 & Maluku & $-0,747$ \\
\hline 9 & Babel & 0,009 & 19 & Kalbar & $-0,343$ & 29 & Mal. Utara & $-0,189$ \\
\hline 10 & Kep.Riau & 0,656 & 20 & Kalteng & $-0,172$ & 30 & Papua & 0,063 \\
\hline
\end{tabular}

dari fixed effect model

Dari hasil regresi data panel pada persamaan (8), maka koefisien regresi tersebut dapat diinterpretasikan sebagai berikut: jika semua variabel bernilai 0 , maka rata-rata pertumbuhan ekonomi sebesar 2,3\%. Jika jumlah mobil barang meningkat $1 \%$ maka pertumbuhan ekonomi akan meningkat $0,0816 \%$. Jika jumlah mobil penumpang meningkat $1 \%$ maka pertumbuhan ekonomi akan meningkat $0,0844 \%$. Jika jumlah motor meningkat $1 \%$ maka pertumbuhan ekonomi akan meningkat $0,0083 \%$. Jika jumlah terminal meningkat $1 \%$ maka pertumbuhan ekonomi akan meningkat $0,0203 \%$. Jika arus pesawat meningkat $1 \%$ maka pertumbuhan ekonomi akan meningkat $0,1435 \%$. Jika arus barang yang melewati pelabuhan meningkat $1 \%$ maka pertumbuhan ekonomi akan meningkat $0,03037 \%$. Panjang jalan dan jumlah bus tidak berpengaruh signifikan terhadap pertumbuhan ekonomi. Nilai koefisien determinasi $\left(R^{2} a d j\right)$ sebesar 0,99 artinya variabel-variabel dalam model mampu menjelaskan keragaman dari pertumbuhan ekonomi sebesar $99 \%$ sedangkan sisanya dijelaskan oleh variabel lain yang tidak terdapat dapat model.

Jumlah mobil barang, mobil penumpang, dan sepeda bermotor pertumbuhan ekonomi disebabkan angkutan tersebut memiliki manfaat dan kontribusi yang paling besar dalam membantu pengalokasian sumber-sumber ekonomi secara optimal, pemindahan dan pergerakan muatan, dan memperlancar kegiatan produksi. Yang paling utama adalah mobil barang seperti truck dan pick up dimana barang-barang baik output maupun input produksi dialokasikan dari suatu tempat ke tempat lainnya. Dengan demikian kegiatan produksi akan berjalan dan PDRB suatu daerah akan meningkat.

Tidak berpengaruhnya jumlah bis terhadap pertumbuhan ekonomi disebabkan bis bukanlah angkutan yang menjadi pilihan untuk memindahkan suatu barang dalam proses kegiatan produksinya. Meskipun jasa angkutan bis memiliki nilai output dalam sektor transportasi dan memberikan kontribusi terhadap PDB, namun jumlah kendaraan bis tersebut memiliki efek multiplier yang kecil dalam proses kegiatan produksi di sektor lain.

Arus pesawat dan arus barang yang melewati pelabuhan berpengaruh positif dan signifikan terhadap pertumbuhan ekonomi. Pada Gambar 5 dan 6 di atas memberikan sinyal bahwa baik penerbangan maupun pelayaran sama-sama memiliki perkembangan yang positif sehingga arus pesawat dan arus barang yang melewati pelabuhan yang merupakan proksi 
Jurnal Ilmiah Ekonomi dan Bisnis

Vol. 16. No.1, Maret 2019: 67-77

EISSN : $2442-9813$

ISSN : $1829-9822$

dari infrastuktur angkutan laut dan udara sama-sama mengalami peningkatan. Peningkatan yang ada menyatakan bahwa keduanya berpengaruh dalam hal pendistribusian barang atau jasa ke wilayah tersebut sehingga pertumbuhan ekonomi di wilayah tersebut ikut berkembang.

Ada beberapa dugaan yang menyebabkan panjang jalan tidak berpengaruh signifikan terhadap pertumbuhan ekonomi. Yang pertama, panjang jalan bukan satu-satunya pendukung utama kelancaran perekonomian di Indonesia. Hal ini disebabkan hampir semua kota-kota besar dengan arus ekonomi yang tinggi di Indonesia sudah memiliki akses jalan yang cukup sehingga tidak memerlukan penambahan panjang jalan lagi. Oleh karenanya, pembangunan jalan perlu dilakukan pada daerah-daerah perdesaan yang minim sumber akses transportasi. Yang kedua, panjang jalan memiliki suatu lag dalam waktu tertentu agar dapat memicu pertumbuhan ekonomi di suatu wilayah. Maksudnya, pertambahan panjang jalan tidak serta merta dapat meningkatkan perekonomian secara langsung namun manfaat tersebut akan dirasakan beberapa tahun setelah jalan tersebut selesai dibangun. Hasil uji kausalitas Granger menunjukkan bahwa varibel panjang jalan memilki hubungan satu arah terhadap PDB dimana panjang jalan mempengaruhi PDB secara signifikan dalam lag satu tahun setelahnya ( $\alpha=10 \%)$.

Dummy individu provinsi dapat diartikan sebagai berikut. Misalnya Aceh bernilai -0,0126, artinya pertumbuhan ekonomi Aceh rata-rata lebih kecil $0,0126 \%$ daripada pertumbuhan ekonomi di provinsi lainnya atau dengan kata lain apabila semua variabel independen bernilai 0 , maka rata-rata pertumbuhan ekonomi Provinsi Aceh adalah 2,383806 $0,01262=2,371186 \%$. Dari hasil diatas, terlihat bahwa Provinsi DKI Jakarta memiliki rata-rata pertumbuhan ekonomi paling tinggi daripada provinsi lainnya, sementara NTT adalah provinsi yang ratarata pertumbuhan ekonominya paling rendah. Hal ini disebabkan Jakarta merupakan ibu kota dan pusat perekonomian di Indonesia sementara di NTT, pembangunan ekonomi terbilang masih tertinggal.

\section{KESIMPULAN DAN SARAN}

Pertumbuhan ekonomi di provinsiprovinsi di Indonesia dipengaruhi oleh infrasktruktur transportasi yang ada. Model regresi data panel yang terbaik adalah model Fixed Effect. Hasil regresi data panel menunjukan bahwa secara bersama-sama infrastruktur transportasi mempengaruhi pertumbuhan ekonomi di Indonesia secara signifikan dengan koefisien determinasi sebesar $99 \%$. Secara parsial, jumlah mobil penumpang, mobil barang, sepeda motor, arus pesawat, dan arus bongkar muat barang dipelabuhan berpengaruh secara signifikan terhadap pertumbuhan ekonomi sementara jumlah bis dan panjang jalan tidak berpengaruh signifkan terhadap pertumbuhan ekonomi.

\section{DAFTAR PUSTAKA}

Badan Pusat Statistik (BPS), Statistik Transportasi, Beberapa Tahun.

Capello R. 2009. Regional Economics. New York: Routledge.

Economic Planning Advisory Commission. 1995, Investment and economic growth. Australian Government Publishing Service Commission Paper 9.

Eliot Hurst. M.E. (1974), Transportation Geography: Comments and Readings, New York: McGraw Hill. 
Kementrian Perhubungan (Kemenhub),

Statistik Perhubungan, Beberapa Tahun.

Mankiw, N. Gregory. 2003. Macroeconomics. Harvard University: Worth Publishers.

Ma'ruf, Yudhi Permadi, Ir. Daud Jeluddin, M.Eng . 2015. Pengaruh investasi terhadap pertumbuhan ekonomi wilayah di Kabupaten Pesisir Selatan. Jurnal Teknik Sipil USU. Vol 02 No. 3.

Maryaningsih, Novi., Hermansyah, O., Savitri, Mi., 2014, Pengaruh Infrastruktur Terhadap Pertumbuhan Ekonomi di Indonesia. Buletin Ekonomi Moneter dan Perbankan. Vol 17. No1. 